\title{
Efeito de Enzimas Fibrolíticas e do Teor de Matéria Seca em Silagens de Capim- Tanzânia sobre os Parâmetros Ruminais, o Comportamento Ingestivo e a Digestão de Nutrientes, em Bovinos ${ }^{1}$
}

\section{Daniele Rebouças Santana Loures ${ }^{2}$, Luiz Gustavo Nussio ${ }^{3}$, Solidete de Fátima Paziani ${ }^{2}$, André de Faria Pedroso ${ }^{4}$, Lucas José Mari ${ }^{5}$, José Leonardo Ribeiro ${ }^{5}$, Maity Zopollatto ${ }^{5}$, Patrick Schmidt ${ }^{5}$, Marta Coimbra Junqueira ${ }^{5}$, Irineu Umberto Packer ${ }^{3}$, Fábio Prudêncio de Campos ${ }^{6}$}

\begin{abstract}
RESUMO - Objetivou-se, com este trabalho, avaliar o efeito do emurchecimento e uso de enzimas fibrolíticas aplicadas durante a ensilagem de capim-tanzânia ( Panicum maximum Jacq. cv. Tanzânia) ou antecedendo o fornecimento aos animais. Foram realizadas avaliações de parâmetros de fermentação e cinética ruminal, comportamento ingestivo, consumo voluntário e digestibilidade dos nutrientes em bovinos. Os tratamentos utilizados consistiram da ensilagem das forragens, conforme descrito: A - forragem emurchecida sem aplicação de enzimas; B - não-emurchecida sem aplicação de enzimas; C - emurchecida com aplicação de enzimas (2 L/t de massa verde); D - não-emurchecida com aplicação de enzimas e E - não-emurchecida com enzimas (10 L/t de massa verde) aplicadas após a abertura do silo e antes da oferta aos animais. Cinco novilhos da raça Nelore foram distribuídos ao acaso em delineamento do tipo quadrado latino 5 x 5, recebendo rações contendo $50 \%$ de silagem na MS. Os parâmetros de cinética de passagem de sólidos (2,23\%/hora) e de líquidos (4,83\%/hora) foram similares nos tratamentos avaliados. As médias das concentrações molares totais dos AGVs (109,62 mM) e de nitrogênio amoniacal (5,6 mg/dL) do fluido ruminal não foram alteradas. O emurchecimento da forragem determinou menor relação C2:C3 ruminal. O comportamento ingestivo dos animais não foi alterado com a adição de enzimas fibrolíticas na ensilagem, sendo observados os seguintes tempos (minutos/dia) e taxas (min/kg MSI): ingestão de MS (247 e 24), ruminação (426 e 43) e mastigação (673 e 67), respectivamente. No caso do emurchecimento, houve menor tempo de ruminação e de mastigação pelos animais. As digestibilidades médias de MS (47,5 vs. 53,6\%), de FDN (45,8 vs. 55\%) e de FDA (45,5 vs. $54,8 \%$ ) foram reduzidas nas rações completas contendo silagens emurchecidas. O emurchecimento da forragem e o uso de aditivo enzimático resultaram em alterações marginais nos parâmetros ruminais e no comportamento ingestivo dos animais.
\end{abstract}

Palavras-chave: aplicação enzimática, enzimas fibrolíticas, comportamento ingestivo, digestibilidade, emurchecimento, Panicum maximum

\section{Fibrolytic Enzymes and Dry Matter Content of Tanzaniagrass Silages on the Ruminal Parameters, Ingestive Behavior and Nutrient Digestion of Bovine}

\begin{abstract}
The present trial aimed to study the effects of forage wilting or the addition fibrolytic enzymes to the Tanzaniagrass (Panicum maximum Jacq. cv. Tanzania) during the ensiling process or after the silage unloading and before animal feeding. The fermentation and ruminal kinetics parameters, animal ingestive behavior, dry matter intake and in vivo nutrient digestibilities in bovine were measured. Treatments consisted of forage ensiling as described: A - wilted forage without enzymes; B - fresh forage without enzymes; C - wilted forage with enzymes at ensiling ( $2 \mathrm{~L} / \mathrm{t}$ wet forage); D - fresh forage with enzymes at ensiling; E - enzymes applied into silage (10 L/t wet silage) 30 minutes before feeding (direct-fed). Silage samples were submitted to chemical analysis and screened for particle size measurements. Five ruminally cannulated Nellore steers were randomly assigned to a 5 x 5 Latin square design and fed with $50 \%$ silage total mixed rations diets. The ruminal passage rate of solid $(2.23 \%$ /hour) and liquid (4.83\%/hour) phases were similar for all treatments. The molar concentration $(109.62 \mathrm{mM})$ of total VFAs and ammonia-N (5.6 mg/dL) observed in ruminal fluid were similar across silages diets. The forage wilting determined lower $\mathrm{C} 2: \mathrm{C} 3$ ration in the rumen. The animal ingestive behavior measured as total time (minutes/day) and rate (minutes/DM kg) was not changed with enzymes application, averaging DM eating (247; 24), DM ruminating $(426 ; 43)$ and DM chewing $(673 ; 67)$, respectively. Rations containing wilted silages showed less rumination and chewing. The mean DM (47.5 vs. 53.6\%), NDF (45.8 vs. 55\%) and ADF (45.5 vs. 54.8\%) digestibilities were decreased on total mixed rations containing wilted silages. The wilting of Tanzaniagrass or the addition of fibrolytic enzymes resulted in marginal improvement, both in the ruminal parameters or animal ingestive behavior.
\end{abstract}

Key Words: digestibility, direct-fed application, fibrolytic enzymes, ingestive behavior, Panicum maximum, wilting

\footnotetext{
1 Parte da tese de Doutorado apresentada à USP/ESALQ pela primeira autora, financiada pela FAPESP.

2 Doutor em Agronomia - Ciência Animal e Pastagens - USP/ESALQ.Av Pádua Dias, 11 - CEP: 13418-900-Piracicaba-SP (dloures@terra.com.br).

${ }^{3}$ Professor do Depto. de Zootecnia da USP/ESALQ. Av. Pádua Dias, 11 - CEP:13418-900. - Piracicaba -SP.

4 Pesquisador da EMBRAPA - Pecuária Sudeste, São Carlos - SP.

${ }^{5}$ Aluno de Pós-Graduação - Ciência Animal e Pastagens - USP/ESALQ. Av Pádua Dias, 11 - CEP: $13418-900$ - Piracicaba - SP.

${ }^{6}$ Pesquisador do Instituto de Zootecnia - Nova Odessa - SP.
} 


\section{Introdução}

$\mathrm{O}$ emurchecimento de forragens úmidas exerce efeito de concentração de substrato, que, juntamente com o aumento do potencial osmótico, dificulta o desenvolvimento de bactérias indesejáveis - principalmente clostrídios - e permite a dominância de bactérias homofermentativas láticas, possibilitando um rápido declínio do $\mathrm{pH}$ e menor extensão da fermentação (Woolford, 1984). Contudo, a extensão desse processo pode afetar a qualidade de fermentação da silagem, caso o emurchecimento se estenda por muitos dias, por haver consumo dos carboidratos solúveis presentes na forragem, redução do teor de $\mathrm{N}$ protéico e aumento da deaminação de aminoácidos (Henderson, 1993).

Geralmente, consideram-se como aditivos de silagens aqueles produtos que podem ser adicionadas às forragens ensiladas para melhorar a fermentação ou reduzir perdas, podendo ser classificados em inibidores e estimuladores de fermentação (Woolford, 1984; Pitt, 1990). A utilização de enzimas fibrolíticas na ensilagem visa aumentar a eficiência do processo fermentativo, favorecendo a atuação de microrganismos desejáveis, como as bactérias produtoras de ácido lático (Muck \& Kung Jr., 1997; Kung Jr., 2000). As principais enzimas fibrolíticas utilizadas, como as hemicelulases, celulases, pectinases e xilanases, atuam disponibilizando açúcares simples como fonte de nutrientes para as bactérias fermentadoras (Muck \& Kung Jr., 1997).

Tem-se verificado que os resultados dos aditivos enzimáticos, tanto na ensilagem de forragens como no preparo de rações, utilizando os métodos in situ ou in vivo, nem sempre são semelhantes, sendo que os resultados in vivo têm sido mais satisfatórios (Beauchemin \& Rode, 1996). Os autores destacam ainda que a aplicação direta das enzimas no ambiente ruminal pode apresentar menor eficiência enzimática que a aplicação direta no alimento fornecido. Alguns autores sugerem que as enzimas fibrolíticas podem ser parcialmente protegidas da degradação ruminal, em decorrência da alteração conformacional provocada por forte ligação com o substrato, quando aplicadas diretamente no alimento fornecido (Fontes et al., 1995).

Em gramíneas e leguminosas com teores mais elevados de matéria seca (MS) e com baixa concentração de açúcares solúveis, a adição de enzimas fibrolíticas pode apresentar resultados satisfatórios graças à liberação de açúcares provenientes da hidrólise da parede celular, fornecendo substrato adicional para produção de ácido lático pelas bactérias (Muck \& Kung Jr., 1997; Beauchemin \& Rode, 1996). Além disso, sua aplicação em materiais com maior teor de MS favorece a formação de complexo enzima-substrato bastante estável, que aumenta a eficiência das enzimas (Beauchemin et al., 2002). A formação desse complexo ocorre em poucas horas e essa estabilidade é mantida por várias semanas, como pode ser verificado em condições laboratoriais e em experimentos de desempenho e comportamento ingestivo de animais (Beauchemin \& Buchanan-Smith, 1989; Beauchemin et al., 2002). Feng et al. (1992), avaliando cinco teores de umidade em gramíneas, verificaram que o emurchecimento em gramíneas de inverno tratadas com enzimas fibrolíticas aumentou a digestão ruminal in vitro da fibra. Contudo, a aplicação das enzimas em forragens úmidas proporcionou redução da degradabilidade da gramínea.

A aplicação de aditivos enzimáticos (celulase) no início da ensilagem permitiu aumentar a degradação do tecido de parênquima em alfafa (Medicago sativa L.) e Phleum pratense L., reduzindo as frações de FDN, FDA, hemicelulose e celulose, fato que não representou, necessariamente, aumento na digestibilidade ruminal (Ishida et al., 2001; Aniwaru et al., 2001).

Atualmente, são encontrados diversos trabalhos sobre aplicação de enzimas fibrolíticas na ensilagem de forragens. Entretanto, as inúmeras variações quanto à padronização das preparações enzimáticas e formas de aplicação, entre outras, proporcionam resultados inconsistentes, tornando difíceis a avaliação e comparação do efeito das enzimas sobre a fermentação da silagem e o desempenho de animais.

Objetivou-se, com este trabalho, avaliar o efeito do emurchecimento, do uso de enzimas fibrolíticas e suas formas de aplicação sobre a composição bromatológica de silagens de capim-tanzânia e os parâmetros ruminais, o comportamento ingestivo e a digestão de nutrientes em bovinos.

\section{Material e Métodos}

Este trabalho foi realizado no Departamento de Zootecnia da Escola Superior de Agricultura "Luiz de Queiroz" (USP/ESALQ). A ensilagem do capimtanzânia (Panicum maximum Jacq. cv. Tanzânia), 
aos 45 dias de crescimento vegetativo, foi realizada em fevereiro de 2002. Durante a ensilagem, a solução de enzimas fibrolíticas foi misturada à forragem, de forma que $150 \mathrm{~g}$ de enzimas fibrolíticas foram diluídos em 100 L de água destilada, sendo 2 L dessa solução aplicados por tonelada de massa verde picada. Quando utilizada como aditivo alimentar, $150 \mathrm{~g}$ da preparação enzimática foram diluídos em $500 \mathrm{~L}$ de água destilada e, dessa solução, foram aplicados $10 \mathrm{~L}$ por tonelada de silagem. Com o objetivo de permitir a ação enzimática, as silagens aditivadas foram mantidas intactas durante 30 minutos e, em seguida, misturadas aos ingredientes concentrados para o fornecimento das rações aos animais.

As forragens colhidas e picadas foram armazenadas em cinco silos tipo poço, com capacidade para $12 \mathrm{t}$ cada, compactadas por pisoteio, vedadas com lona plástica de $200 \mu$ de espessura e preservadas por 62 dias antes da abertura. Diariamente, as silagens foram avaliadas quanto ao aspecto sensorial e foi ofertada aos animais a porção considerada satisfatória, descartando-se a silagem deteriorada.

Tabela 1 - Características bromatológicas e fermentativas das silagens de capim-tanzânia, do concentrado e das rações experimentais

Table 1 - Chemical and fermentative parameters of Tanzaniagrass silage, concentrate and experimental rations

\begin{tabular}{|c|c|c|c|c|c|c|c|c|c|c|c|}
\hline \multirow[t]{2}{*}{$\begin{array}{l}\text { Variável } \\
\text { Variable }\end{array}$} & \multirow[t]{2}{*}{$\begin{array}{l}\text { grediente concentrado } \\
\text { Concentrate }\end{array}$} & \multicolumn{5}{|c|}{$\begin{array}{l}\text { Ingrediente-Silagem }^{1} \\
\text { Ingredient - Silage }\end{array}$} & \multicolumn{5}{|c|}{$\begin{array}{c}\text { Ração - Tratamento } \\
\text { Ration - Treatment }\end{array}$} \\
\hline & & $\mathrm{A}$ & B & $\mathrm{C}$ & $\mathrm{D}$ & $E$ & $\mathrm{~A}$ & B & $\mathrm{C}$ & $\mathrm{D}$ & $E$ \\
\hline $\begin{array}{l}\text { Matéria seca, \% } \\
\text { Dry matter, } \%\end{array}$ & 85,4 & 24,2 & 20,6 & 23,9 & 21,5 & 21,7 & 54,99 & 53,18 & 54,84 & 53,64 & 53,74 \\
\hline $\begin{array}{l}\mathrm{MO}, \%^{3} \\
O M, \%\end{array}$ & 94,5 & 87,6 & 90,2 & 87,4 & 89,1 & 90,2 & 91,05 & 92,33 & 90,93 & 91,82 & 92,33 \\
\hline $\begin{array}{l}\text { Cinzas, \% MS } \\
\text { Ash, \% DM }\end{array}$ & 5,55 & 12,4 & 9,8 & 12,6 & 10,8 & 9,8 & 8,95 & 7,68 & 9,07 & 8,17 & 7,67 \\
\hline $\begin{array}{l}\mathrm{PB}, \% \mathrm{MS}^{4} \\
C P, \% D M\end{array}$ & 22,9 & 5,92 & 2,71 & 6,07 & 2,54 & 2,77 & 14,45 & 12,86 & 14,53 & 12,77 & 12,89 \\
\hline $\begin{array}{l}\mathrm{EE}, \% \mathrm{MS}^{5} \\
E E, \% D M\end{array}$ & 4,47 & 1,91 & 2,20 & 1,81 & 2,10 & 2,21 & 3,20 & 3,34 & 3,15 & 3,29 & 3,35 \\
\hline $\begin{array}{l}\text { FDN, \% MS } \\
N D F, \% D M\end{array}$ & 31,1 & 71,5 & 76,5 & 70,0 & 73,7 & 77,1 & 51,17 & 53,66 & 50,46 & 52,30 & 53,96 \\
\hline $\begin{array}{l}\text { FDA, \% } \mathrm{MS}^{7} \\
A D F, \% D M\end{array}$ & 8,5 & 45,2 & 49,0 & 44,1 & 46,0 & 49,6 & 26,74 & 28,62 & 26,17 & 27,12 & 28,90 \\
\hline $\begin{array}{l}\text { CEL, \% } \mathrm{MS}^{8} \\
C E L, \% D M\end{array}$ & 5,4 & 37,9 & 41,8 & 35,4 & 38,9 & 41,9 & 21,58 & 23,51 & 20,35 & 22,08 & 23,55 \\
\hline $\begin{array}{l}\text { HEMI, \% MS } \\
\text { HEMI, \%DM }\end{array}$ & 22,6 & 26,2 & 27,5 & 26,0 & 27,8 & 27,5 & 24,42 & 25,03 & 24,28 & 25,17 & 25,06 \\
\hline $\begin{array}{l}\mathrm{CS}, \% \mathrm{MS}^{10} \\
S C, \% D M\end{array}$ & 2,81 & 0,73 & 0,48 & 1,10 & 0,47 & 0,52 & - & - & - & - & - \\
\hline $\begin{array}{l}\mathrm{LIG}, \% \mathrm{MS}^{11} \\
L I G, \% D M\end{array}$ & 2,89 & 5,39 & 5,14 & 5,60 & 4,70 & 5,29 & 4,13 & 4,01 & 4,24 & 3,79 & 4,08 \\
\hline $\begin{array}{l}\mathrm{CNF}^{2}, \% \mathrm{MS}^{12} \\
N F C, \% D M\end{array}$ & 36,0 & 8,3 & 8,8 & 9,4 & 10,8 & 8,1 & 22,23 & 22,45 & 22,79 & 23,46 & 22,14 \\
\hline $\begin{array}{l}\mathrm{N}-\mathrm{NH}_{3}, \% \text { N-Total } \\
\mathrm{N}-\mathrm{NH}_{3}, \% \text { Total } N \\
\text { pH }\end{array}$ & l & 8,05 & 20,35 & 5,15 & 19,0 & 19,4 & - & - & - & - & - \\
\hline
\end{tabular}

Participação de ingredientes nas rações: $49,69 \%$ de silagem de capim-tanzânia, $47,18 \%$ de milheto grão moído, 1,67\% de uréia e 1,46\% de premix mineral vitamínico (Ingredient composition : $49.69 \%$ of Tanzaniagrass silage, $47.18 \%$ of ground pearl millet grain, $1.67 \%$ of urea and $1.46 \%$ of mineral premix).

${ }^{1}$ Silagem = A - silagem emurchecida; B - silagem sem emurchecimento; C - silagem emurchecida com enzimas; D - silagem sem emurchecimento com enzimas; $\mathrm{E}$ - silagem sem emurchecimento com enzimas aplicadas após abertura do silo. (Treatments $=A$ - wilted forage, without enzymes; $B$ - fresh forage, without enzymes; $C$ - wilted forage with enzymes at ensiling; $D$ - fresh forage, with enzymes at ensiling; $E$ - fresh forage with enzymes applied onto silage 30 minutes before feeding (direct-fed)).

${ }^{2} \mathrm{CNF}=100-[\mathrm{FDN}+\mathrm{EE}+\mathrm{PB}+\mathrm{MM}](\mathrm{NFC}=100-[\mathrm{NDF}+E E+C P+$ Ash $])$

${ }^{3}$ Matéria orgânica (Organic matter), ${ }^{4}$ Proteína bruta (Crude protein), ${ }^{5}$ Extrato etéreo (Ether extract), ${ }^{6}$ Fibra em detergente neutro (Neutral detergent fiber), ${ }^{7}$ Fibra em detergente ácido (Acid detergent fiber), ${ }^{8}$ Celulose (Cellulose), ${ }^{9}$ Hemicelulose (Hemicellulose), ${ }^{10}$ Carboidratos solúveis (Soluble carbohydrates), ${ }^{11}$ Lignina (Lignin); ${ }^{12}$ Carboidratos não-fibrosos (Nonfiber carbohydrates).

NTotal = nitrogênio total (Total nitrogen). 
Os teores de nutrientes analisados das silagens de capim-tanzânia e dos concentrados e as estimativas de valor nutritivo das rações completas encontram-se na Tabela 1.

O delineamento adotado foi o quadrado latino $5 \times 5$, com cinco tratamentos e cinco períodos de avaliação. O período experimental iniciou-se no dia 8 de abril de 2002, com duração de 70 dias, subdividido em cinco períodos de 14 dias (sete dias para adaptação dos animais às rações e sete para coleta de amostras). Neste experimento, foram utilizados cinco bovinos machos castrados da raça Nelore, com peso médio inicial de $454 \mathrm{~kg}$, mantidos em galpão coberto contendo baias individuais de 1,06 $\mathrm{m}$ de largura, com comprimento ajustável de acordo com o tamanho do animal, providas de comedouro, bebedouro automático e piso emborrachado. As rações foram fornecidas ad libitum, duas vezes ao dia $(8$ e $17 \mathrm{~h})$, permitindo-se $5 \%$ de sobras. A quantidade total de silagem destinada aos animais era retirada do silo pela manhã, sendo fornecidos $70 \%$ da ração às $8 \mathrm{~h}$ e os $30 \%$ restantes, às $17 \mathrm{~h}$. As sobras foram mensuradas todas as manhãs, para ajuste e avaliação do consumo de MS. A amostragem diária das silagens e das sobras era realizada considerando-se sempre 5\% do total, para formação de uma amostra composta ao final de cada período de coleta, armazenada em congelador para posteriores análises laboratoriais.

No primeiro dia de coleta, foram avaliadas as atividades de comportamento ingestivo dos animais a cada cinco minutos, por 24 horas, registrando-se a freqüência de ingestão de água, ruminação, ingestão de alimento e ócio (Maekawa et al., 2002).

No terceiro dia de coleta, amostras de fluido ruminal foram coletadas, diretamente do rúmen, antes da alimentação matinal e a cada duas horas após o fornecimento da ração. Após a mensuração do $\mathrm{pH}$ ruminal, uma alíquota de aproximadamente $50 \mathrm{~mL}$ foi transferida para dois frascos distintos, armazenados em congelador, para posterior determinação de nitrogênio amoniacal (Chaney \& Marbach, 1962) e concentração molar de ácidos graxos voláteis, conforme Palmquist \& Conrad (1971).

No quarto dia de cada período de avaliação, pela manhã, $100 \mathrm{~g}$ de amostras das silagens marcadas com cromo mordente foram introduzidos no rúmen, com o objetivo de determinar a taxa de passagem dos sólidos da digesta ruminal, além de uma solução de Co-EDTA, para se determinar a taxa de passagem da fase líquida (1L de solução contendo $3 \mathrm{~g}$ de CoEDTA), de acordo com metodologia descrita por Udén et al. (1980).

Nesse mesmo dia, também iniciou-se a amostragem de fezes, que foram coletadas no reto. Amostras de fezes coletadas diretamente do reto às $0,6,12,18,24,30$, $36,42,48,54,60,66,72,78,84$ e 90 horas após a dosagem dos marcadores foram, imediatamente, colocadas em estufa a $60^{\circ} \mathrm{C}$, com ventilação forçada, durante 72 horas.

Nos dias 4, 5, 6 e 7, de cada período de coleta, foi realizada a coleta total de fezes, quantificadas às 8 e 20 horas, homogeneizando-se $5 \%$ do total amostrado para constituir uma amostra composta do tratamento no período. As determinações das digestibilidades aparentes da MS, matéria orgânica (MO), FDN, FDA e hemicelulose no trato total foram realizadas mediante quantificação total das fezes produzidas pelos animais.

Ao final dos períodos de coleta, as amostras de silagem, concentrado e sobras armazenadas foram descongeladas, secas em estufa de circulação forçada a $60^{\circ} \mathrm{C}$ por 72 horas, moídas a $1 \mathrm{~mm}$ e, posteriormente, submetidas às seguintes análises químicobromatológicas: MM e extrato etéreo (EE), conforme AOAC (1990); FDN, FDA e lignina, segundo Van Soest et al. (1991); e MS, de acordo com Silva (1990).

Para as análises de carboidratos solúveis e nitrogênio amoniacal, foram preparados extratos aquosos da silagem, conforme Kung Jr. et al. (1984). Posteriormente, para análise de carboidratos solúveis, foi utilizada a metodologia proposta por Dubois et al. (1956) e, para nitrogênio amoniacal, seguiu-se o método colorimétrico descrito por Okuda et al. (1965).

A determinação de nitrogênio foi obtida por meio da combustão da amostra, segundo o método de Dumas (Wiles et al., 1998). As frações FDN e FDA foram determinadas com auxílio do equipamento "Fiber Analyser Ankon 2000". A lignina foi obtida pelo método LDA (lignina em detergente ácido), pelo uso de solução de ácido sulfúrico a 72\%, após a determinação de FDA, utilizando o equipamento "Daisy Incubator Ankon".

A estratificação de partículas nas amostras de silagens foi realizada por meio de adaptação da metodologia das peneiras do "Penn State Particle Size Separator", proposta por Lammers et al. (1996).

Os dados das amostras incubadas foram processados por intemédio do programa "Fit Curve", desenvolvido pelo Rowett Research Institute. O programa oferece os parâmetros do modelo de degradabilidade 
ruminal, segundo Orskov \& McDonald (1979), entre outras informações.

Os dados foram analisados pelo programa GLM do SAS (2000). A fim de se permitir comparações de digestão de nutrientes, comportamento ingestivo, ingestão de MS e digestibilidade aparente entre tratamentos e grupos de tratamentos, foram estabelecidos os seguintes contrastes ortogonais: entre tratamentos com emurchecimento e tratamentos sem emurchecimento $(\mathrm{A}+\mathrm{C}$ vs. $\mathrm{B}+\mathrm{D}+\mathrm{E})$; entre tratamentos com emurchecimento com e sem adição de enzimas (A vs. C); entre tratamentos sem emurchecimento com e sem adição de enzimas (B vs. $\mathrm{D}+\mathrm{E})$; e entre tratamentos sem emurchecimento com enzima fibrolítica aplicada na ensilagem e com enzimas fibrolíticas aplicadas 30 minutos antes de a silagem ser fornecida aos animais (D vs. E). Os parâmetros ruminais de $\mathrm{pH}, \mathrm{AGV}$ e $\mathrm{N}$ amoniacal foram analisados como medidas repetidas para cada tratamento, animal e período experimental, utilizandose o PROC MIXED do mesmo programa estatístico.

As diferenças entre os tratamentos, para as diversas variáveis, foram analisadas adotando-se os níveis de significância de 1,5 e $10 \%$ de probabilidade.

\section{Resultados e Discussão}

Foram observados teores médios de MS típicos para as silagens de gramíneas tropicais sem emurchecimento $(21,24 \%)$ (Tabela 1$)$. No caso das silagens emurchecidas por cinco horas, os teores alcançados $(24,06 \%)$ foram inferiores ao planejado $(30 \%)$, provavelmente em virtude das condições climáticas predominantes.

Nas silagens emurchecidas, foi observada manutenção no teor de PB $(6 \%)$ em relação à forragem original, o que pode ser atribuído à menor incidência de proteólise e deaminação (Igarasi, 2002). O baixo teor de $\mathrm{PB}$ das silagens úmidas $(2,67 \%)$ poderia também ser explicado pelas perdas ocorridas no manuseio de amostras, proporcionando perdas na fração nitrogenada associadas à lise de proteínas, que podem ser confirmadas verificando-se os elevados teores de nitrogênio amoniacal nas silagens, apresentados na Tabela 1.

Os resultados das avaliações sobre os parâmetros ruminais podem ser verificados na Tabela 2. Foi detectada diferença significativa para os valores de $\mathrm{pH}$ ruminal, em função do tratamento $(\mathrm{P}<0,10)$ e horário de coleta $(\mathrm{P}<0,05)$; contudo, não foi verificada interação entre tratamento e do horário de coleta $(\mathrm{P}>0,10)$. O contraste entre os tratamentos com silagens emurchecidas e não-emurchecidas $(\mathrm{A}+\mathrm{C}$ vs. $\mathrm{B}+\mathrm{D}+\mathrm{E}$ ) foi realizado para verificar se houve efeito do teor de MS sobre o $\mathrm{pH}$. Por meio de análise estatística, constatou-se que não houve diferença significativa $(\mathrm{P}>0,05)$ entre os tratamentos. Também não houve efeito $(\mathrm{P}>0,10)$ de contraste (B vs. $\mathrm{D}+\mathrm{E}$ e D vs. E) para os tratamentos que constaram do uso de enzimas fibrolíticas em silagens sem emurchecimento. No entanto, ao avaliar o uso de enzimas fibrolíticas em silagens com emurchecimento, observou-se efeito significativo $(\mathrm{P}<0,05)$ desses tratamentos (A vs. C) sobre o $\mathrm{pH}$ ruminal.

Verificou-se queda mais acentuada do $\mathrm{pH}$ ruminal, com a aplicação das enzimas fibrolíticas em silagens emurchecidas (A vs. C), entretanto essa queda de $\mathrm{pH}$, não foi suficiente para acarretar impacto negativo na digestibilidade da fibra. Ao observar os teores estimados de CNF das rações experimentais (Tabela 1), também torna-se evidente associar a queda de $\mathrm{pH}$ ruminal com alterações nessa fração que foram mínimas. Os resultados observados neste experimento, em relação ao pH ruminal, indicam que as condições foram favoráveis ao melhor aproveitamento da fibra em todos os tratamentos.

No caso de a enzima ser aplicada na silagem antes do fornecimento ao animal existe a preocupação quanto à sua atividade no ambiente ruminal. Embora a atividade celulolítica microbiana, em geral, diminua com a redução do $\mathrm{pH}$ no rúmen, algumas preparações enzimáticas de celulase-hemicelulase proporcionam atividade fibrolítica satisfatória em $\mathrm{pH} 4,5$, o que poderia, inclusive, minimizar os efeitos depressores da digestão da fibra durante períodos de baixo $\mathrm{pH}$ (Pitt, 1990).

A concentração molar de ácidos graxos voláteis (AGVs), a razão entre acetato e propionato e a concentração total de ácidos graxos foram avaliados em função do tempo. As variáveis que apresentaram efeito da interação tratamento*horário foram analisadas de acordo com os contrastes. Não foram detectadas diferenças significativas $(\mathrm{P}>0,10)$ para as concentrações de ácidos graxos analisadas isoladamente em função do tratamento. Não houve efeito da interação tratamento*horário para as concentrações do acetato, do ácido butírico e do total de ácidos graxos. 
Tabela 2 - Parâmetros ruminais dos animais alimentados com rações contendo silagens de capim-tanzânia Table 2 - Ruminal parameters of animals fed rations containing Tanzaniagrass silages

\begin{tabular}{|c|c|c|c|c|c|c|c|c|c|c|c|c|}
\hline \multirow[t]{2}{*}{$\begin{array}{l}\text { Variável } \\
\text { Variable }\end{array}$} & \multicolumn{5}{|c|}{$\begin{array}{c}\text { Tratamentos } \\
\text { Treatments }\end{array}$} & \multicolumn{3}{|c|}{$\begin{array}{c}\text { Efeitos e interação }(\mathrm{P}<) \\
\text { Effects and interactions }\end{array}$} & \multicolumn{4}{|c|}{$\begin{array}{c}\text { Contrastes }(\mathrm{P}<)^{2} \\
\text { Contrasts }\end{array}$} \\
\hline & A & B & $\mathrm{C}$ & $\mathrm{D}$ & $\mathrm{E}$ & $\begin{array}{l}\text { Trat } \\
\text { Treat. }\end{array}$ & $\begin{array}{c}\text { Horário } \\
\text { Hour }\end{array}$ & $\begin{array}{l}\text { Trat*Horário } \\
\text { Treat*Hour }\end{array}$ & 1 & 2 & 3 & 4 \\
\hline \multicolumn{13}{|c|}{ Concentração molar de AGV (mM) } \\
\hline Acético (acetic) & 71,99 & 74,14 & 78,64 & 75,10 & 80,61 & $\mathrm{~ns}$ & $* *$ & $\mathrm{~ns}$ & $\mathrm{~ns}$ & $\mathrm{~ns}$ & $\mathrm{~ns}$ & $\mathrm{~ns}$ \\
\hline Propiônico (propionic) & 17,85 & 16,20 & 18,14 & 16,87 & 18,64 & $\mathrm{~ns}$ & $* *$ & $\mathrm{~ns}$ & $\mathrm{~ns}$ & $\mathrm{~ns}$ & $\mathrm{~ns}$ & $\mathrm{~ns}$ \\
\hline Butírico (butiric) & 11,85 & 12,70 & 11,71 & 12,21 & 13,38 & $\mathrm{~ns}$ & $* *$ & $* *$ & $\mathrm{~ns}$ & $\mathrm{~ns}$ & $\mathrm{~ns}$ & $\mathrm{~ns}$ \\
\hline Isobutírico (isobutiric) & 1,02 & 1,03 & 0,92 & 0,97 & 1,14 & $\mathrm{~ns}$ & $* *$ & $\dagger$ & $\mathrm{ns}$ & $\mathrm{ns}$ & $\mathrm{ns}$ & $\mathrm{ns}$ \\
\hline Valérico(valeric) & 0,86 & 1,00 & 0,94 & 0,98 & 1,12 & $\mathrm{~ns}$ & $* *$ & $* *$ & $\mathrm{~ns}$ & $\mathrm{~ns}$ & $\mathrm{~ns}$ & $\mathrm{~ns}$ \\
\hline Isovalérico (isovaleric) & 1,39 & 1,86 & 1,46 & 1,65 & 1,70 & $\mathrm{~ns}$ & $* *$ & $* *$ & $\dagger$ & $\mathrm{ns}$ & $\mathrm{ns}$ & $\mathrm{ns}$ \\
\hline $\mathrm{C} 2: \mathrm{C}^{3}$ & 4,07 & 4,56 & 4,31 & 4,49 & 4,35 & $* *$ & $* *$ & $\dagger$ & $* *$ & $*$ & $\mathrm{~ns}$ & $\mathrm{~ns}$ \\
\hline TOTAL & 104,96 & 106,95 & 111,82 & 107,80 & 116,61 & $\mathrm{~ns}$ & $* *$ & $\mathrm{~ns}$ & $\mathrm{~ns}$ & $\mathrm{~ns}$ & $\mathrm{~ns}$ & $\mathrm{~ns}$ \\
\hline $\mathrm{pH}$ & 6,48 & 6,36 & 6,21 & 6,44 & 6,34 & $\dagger$ & $* *$ & $\mathrm{~ns}$ & $\mathrm{~ns}$ & $* *$ & $\mathrm{~ns}$ & $\mathrm{~ns}$ \\
\hline $\mathrm{N}-\mathrm{NH}_{3}(\mathrm{mg} / \mathrm{dL})$ & 5,39 & 5,12 & 4,50 & 6,14 & 6,60 & $\mathrm{~ns}$ & $* *$ & $\mathrm{~ns}$ & $\mathrm{~ns}$ & $\mathrm{~ns}$ & $\mathrm{~ns}$ & $\mathrm{~ns}$ \\
\hline
\end{tabular}

\footnotetext{
${ }^{1}$ Tratamentos = A - silagem emurchecida; B - silagem sem emurchecimento; C - silagem emurchecida com enzimas; D - silagem sem emurchecimento com enzimas; $\mathrm{E}$ - silagem sem emurchecimento com enzimas aplicadas após abertura do silo (Treatments $=A$ - wilted forage, without enzymes; $B$ - fresh forage, without enzymes; $C$ - wilted forage with enzymes at ensiling; $D$ - fresh forage, with enzymes at ensiling; $E$ - fresh forage with enzymes applied onto silage 30 minutes before feeding (direct-fed)).

${ }^{2}$ Contrastes $=1$. Efeito emurchecimento $(A+C$ vs. $B+D+E)$, 2. Efeito enzimas - emurchecimento (A vs. $\left.C\right)$, 3. Efeito enzimas - sem emurchecimento (B vs. $D+E)$, 4. Efeito do momento de aplicação da enzima (D vs. E).

${ }^{2}$ Contrasts $=1$. Wilting effect $(A+C$ versus $B+D+E) ; 2$, Enzymes effect - wilting $(A$ vs. $C)$. 3. Enzymes effect - wet $(B$ vs. $D+E)$ and 4 . Enzymes application time (D vs. E).

${ }^{3}$ Relação ácido acético (C2): ácido propiônico (C3) (Acetic acid (C2): Propionic acid (C3) ratio).

ns não-significativo, ${ }^{*}(P<0,05),{ }^{* *}(P<0,01), \dagger(P<0,10)$ (ns: not significant , ${ }^{*}(P<.05),{ }^{* *}(P<.01),+(P<.10)$.
}

A adição de enzimas fibrolíticas em silagens emurchecidas (A vs. C) aumentou significativamente $(\mathrm{P}<0,05)$ a razão entre acetato e propionato (de 4,07 para $4,31 \mathrm{mM}$ ), caracterizando condições mais favoráveis para a digestão ruminal, ainda que tenha havido discreta, porém significativa $(\mathrm{P}<0,01)$, redução do $\mathrm{pH}$ do rúmen.

Quanto ao padrão de fermentação ruminal, podese verificar que a concentração molar média do total de ácidos graxos é de 109,62 mM/L de líquido do rúmen. Em termos de proporção molar, os ácidos acético, propiônico, butírico, isobutírico, valérico e isovalérico representaram $69,16,11,1,0,89$ e 1,5\%, respectivamente. Esses resultados refletem um padrão de fermentação ruminal adequado para a manutenção da biodiversidade dos microrganismos do rúmen, sem comprometimento da digestibilidade da fibra (Bergman, 1990; Coelho, 2002).

Quanto ao teor de nitrogênio amoniacal no rúmen, não houve diferença $(\mathrm{P}>0,10)$ entre os tratamentos estudados, o que está de acordo com os resultados obtidos por Lewis et al. (1996) e Martins et al. (2002), que não constataram diferenças nos parâmetros ruminais ( $\mathrm{pH}$ e nitrogênio amoniacal) com a suplementação enzimática.
O teor médio de nitrogênio amoniacal no rúmen foi de 5,6 $\mathrm{mg} / \mathrm{dL}$ para os tratamentos, sendo essa concentração adequada para o máximo desenvolvimento dos microrganismos ruminais. Nesse sentido, Satter e Slyter (1974) comprovaram, in vitro, que concentrações de nitrogênio amoniacal superiores a $5 \mathrm{mg} / \mathrm{dL}$ de fluido ruminal representam um excesso que é utilizado para síntese microbiana. Apesar disso, há evidências de que maiores concentrações de nitrogênio amoniacal promovem efeitos positivos no ambiente ruminal (Huber \& Kung Jr., 1981). Considerando-se que as condições do ambiente ruminal estiveram sempre favoráveis ao crescimento e à ação de microrganismos ruminais, todos os tratamentos impostos ofereceram condições adequadas para o processo de fermentação.

Os dados obtidos sobre o comportamento ingestivo dos animais encontram-se na Tabela 3. O tempo médio de ingestão dos alimentos, durante o período de análise do comportamento ingestivo dos animais, não foi diferente entre os tratamentos $(\mathrm{P}>0,10)$, com os animais utilizando, em média, 247 minutos para suas refeições. A análise pelo teste $\mathrm{F}$ não acusou diferença significativa $(\mathrm{P}>0,10)$ entre os tratamentos para os tempos médios de ócio (748 minutos) e ingestão de água (17 minutos). 
Tabela 3 - Variáveis do comportamento ingestivo de bovinos de corte

Table 3 - Variables of ingestive behavior of beef steers

\begin{tabular}{|c|c|c|c|c|c|c|c|c|c|c|c|}
\hline \multirow[t]{2}{*}{$\begin{array}{l}\text { Variável } \\
\text { Variable }\end{array}$} & \multicolumn{5}{|c|}{$\begin{array}{l}\text { Tratamento } \\
\text { Treatment }\end{array}$} & \multirow[t]{2}{*}{$\begin{array}{l}\mathrm{CV}(\%) \\
C V(\%)\end{array}$} & \multirow[t]{2}{*}{$\begin{array}{l}\text { Média } \\
\text { Mean }\end{array}$} & \multicolumn{4}{|c|}{$\begin{array}{c}\text { Contraste }(\mathrm{P}<)^{2} \\
\text { Contrast }\end{array}$} \\
\hline & A & $\mathrm{B}$ & $\mathrm{C}$ & $\mathrm{D}$ & $\mathrm{E}$ & & & 1 & 2 & 3 & 4 \\
\hline \multicolumn{12}{|l|}{ Ingestão (Intake) } \\
\hline $\mathrm{min} / \mathrm{dia}(\mathrm{min} /$ day $)$ & 247 & 262 & 241 & 247 & 238 & 13 & 247 & $\mathrm{~ns}$ & $\mathrm{~ns}$ & $\mathrm{~ns}$ & $\mathrm{~ns}$ \\
\hline $\mathrm{min} / \mathrm{kg}$ MSI $(\mathrm{min} / \mathrm{kg} D M I)$ & 22 & 27 & 24 & 24 & 25 & 18 & 24 & $\mathrm{~ns}$ & $\mathrm{~ns}$ & $\mathrm{~ns}$ & $\mathrm{~ns}$ \\
\hline $\mathrm{min} / \mathrm{kg}^{-} \mathrm{FDN}(\min / \mathrm{kg} N D F I)$ & 44 & 50 & 46 & 46 & 47 & 19 & 47 & $\mathrm{~ns}$ & $\mathrm{~ns}$ & $\mathrm{~ns}$ & $\mathrm{~ns}$ \\
\hline \multicolumn{12}{|l|}{ Ruminação (Rumination) } \\
\hline $\mathrm{min} / \mathrm{dia}(\min /$ day $)$ & 427 & 443 & 391 & 430 & 439 & 5 & 426 & $* *$ & $*$ & $\mathrm{~ns}$ & $\mathrm{~ns}$ \\
\hline $\mathrm{min} / \mathrm{kg} \mathrm{MSI}(\mathrm{min} / \mathrm{kg} D M I)$ & 40 & 46 & 39 & 43 & 46 & 8 & 43 & $* *$ & $\mathrm{~ns}$ & $\mathrm{~ns}$ & $\mathrm{~ns}$ \\
\hline $\mathrm{min} / \mathrm{kg}$ FDN $(\mathrm{min} / \mathrm{kg} N D F I)$ & 79 & 85 & 76 & 82 & 87 & 10 & 82 & $*$ & $\mathrm{~ns}$ & $\mathrm{~ns}$ & $\mathrm{~ns}$ \\
\hline \multicolumn{12}{|l|}{ Mastigação (Chewing) } \\
\hline $\mathrm{min} / \mathrm{dia}(\mathrm{min} /$ day $)$ & 674 & 705 & 633 & 677 & 676 & 5 & 673 & $*$ & $\mathrm{~ns}$ & $\mathrm{~ns}$ & $\mathrm{~ns}$ \\
\hline $\mathrm{min} / \mathrm{kg} \mathrm{MSI}(\mathrm{min} / \mathrm{kg} D M I)$ & 62 & 73 & 63 & 66 & 71 & 10 & 67 & $* *$ & $\mathrm{~ns}$ & $\mathrm{~ns}$ & $\mathrm{~ns}$ \\
\hline $\mathrm{min} / \mathrm{kg}$ FDN $(\mathrm{min} / \mathrm{kg} N D F I)$ & 123 & 136 & 122 & 128 & 134 & 12 & 128 & $\mathrm{~ns}$ & $\mathrm{~ns}$ & $\mathrm{~ns}$ & $\mathrm{~ns}$ \\
\hline \multicolumn{12}{|l|}{ Ócio (Idling) } \\
\hline $\min / \mathrm{dia}(\mathrm{min} / d a y)$ & 746 & 715 & 787 & 737 & 753 & 6 & 748 & $\dagger$ & $\mathrm{ns}$ & $\mathrm{ns}$ & $\mathrm{ns}$ \\
\hline \multirow{2}{*}{$\begin{array}{l}\text { Ingestão de água (Water intake) } \\
\mathrm{min} / \mathrm{dia}(\mathrm{min} / \text { day })\end{array}$} & & & & & & & & & & & \\
\hline & 20 & 20 & 20 & 13 & 11 & 70 & 17 & $\mathrm{~ns}$ & $\mathrm{~ns}$ & $\mathrm{~ns}$ & $\mathrm{~ns}$ \\
\hline
\end{tabular}

${ }^{1}$ Tratamentos = A - silagem emurchecida; B - silagem sem emurchecimento; C - silagem emurchecida com enzimas; D - silagem sem emurchecimento com enzimas; $\mathrm{E}$ - silagem sem emurchecimento com enzimas aplicadas após abertura do silo (Treatments $=A$ - wilted forage, without enzymes; $B$ - fresh forage, without enzymes; $C$ - wilted forage with enzymes at ensiling; $D$ - fresh forage, with enzymes at ensiling; $E$ - fresh forage with enzymes applied onto silage 30 minutes before feeding (direct-fed)).

${ }^{2}$ Contrastes $=1$. Efeito emurchecimento $(A+C$ vs. $B+D+E)$, 2. Efeito enzimas - emurchecimento (A vs. C), 3. Efeito enzimas - sem emurchecimento (B vs. $D+E)$, 4. Efeito do momento de aplicação da enzima ( $D$ vs. $E)$.

${ }^{2}$ Contrasts $=1$. Wilting effect $(A+C$ versus $B+D+E) ; 2$, Enzymes effect -wilting $(A$ vs. $C)$. 3. Enzymes effect - wet $(B$ vs. $D+E)$ and 4 . Enzymes application time (D vs. E).

$\mathrm{kg} \mathrm{MSI}=$ matéria seca ingerida ao longo de 24 horas, $\mathrm{kg} F D N I=F D N$ ingerido ao longo de 24 horas ( $\mathrm{kgIDM}=$ Intake of dry matter in 24 hour, $\mathrm{kg}$ INDF = Intake of NDF in 24 hours.

ns: não-significativo, ${ }^{*}(P<0,05),{ }^{* *}(P<0,01), \dagger(P<0,10)$ (ns: not significant, $\left.{ }^{*}(P<.05),{ }^{* *}(P<.01), \dagger(P<.10)\right)$.

No entanto, para ingestão de água, o coeficiente de variação se mostrou elevado (70\%), em virtude de uma ampla variação individual no consumo de água.

Não se detectou efeito $(\mathrm{P}>0,10)$, pelo teste $\mathrm{F}$, entre os tratamentos para a taxa de ingestão de MS, observando-se a taxa média de ingestão de $24 \mathrm{~min} / \mathrm{kg}$ de MS. Para as taxas de ruminação e mastigação, verificou-se efeito significativo $(\mathrm{P}<0,05)$ entre os grupos de tratamentos com e sem o emurchecimento. O tempo de ruminação e mastigação total em $\mathrm{min} / \mathrm{kg}$ de MS diminuiu $(\mathrm{P}<0,01)$ nas rações contendo silagens emurchecidas, apesar de o tempo médio de ingestão de MS não ter apresentado diferença entre os tratamentos. $\mathrm{O}$ fato de o consumo de MS dessas rações ter sido maior pode estar associado ao menor tempo gasto com ruminação e mastigação.

Avaliando as diferenças obtidas entre tamanhos de partícula da forragem, verificou-se que aproximadamente 70 e $50 \%$ das forragens não-emurchecida e emurchecida, respectivamente, apresentavam-se acima de $38 \mathrm{~mm}$, o que sugere que o maior tamanho médio de partículas das silagens úmidas pode ter sido suficiente para promover elevação nos tempos de ruminação e mastigação.

O tamanho apropriado de partícula da forragem é importante para o adequado funcionamento do rúmen. Portanto, a intensa redução do tamanho de partícula da forragem poderia reduzir o tempo de mastigação, causando decréscimo do volume de saliva produzida para tamponar o rúmen e, conseqüentemente, provocando queda de $\mathrm{pH}$. Segundo Mertens (1997), forragens com tamanhos de partículas inferiores a $40 \mathrm{~mm}$ reduzem em $80 \%$ a atividade de mastigação quando comparadas à forragem original, sem a picagem.

$\mathrm{O}$ efeito significativo $(\mathrm{P}<0,05)$ do uso de enzimas fibrolíticas sobre o comportamento ingestivo foi observado somente em dietas contendo silagens de capim-tanzânia emurchecido, havendo redução do tempo de ruminação de $427 \mathrm{~min} /$ dia para $391 \mathrm{~min} /$ dia. Apesar disso, nem a utilização de enzimas fibrolíticas ou sua forma de aplicação promoveram alterações $(\mathrm{P}>0,10)$ na taxa média de passagem ruminal de 
sólidos $(2,23 \% / \mathrm{h})$ e líquidos $(4,83 \% / \mathrm{h})$. A cinética ruminal também não foi alterada pela prática do emurchecimento. Semelhantemente ao ocorrido para a taxa de passagem, não houve efeito significativo $(\mathrm{P}>0,10)$ sobre a ingestão de MS dos tratamentos com ou sem enzimas fibrolíticas.

Os resultados sobre consumo e digestibilidade aparente das variáveis analisadas encontram-se na Tabela 4. $\mathrm{O}$ consumo de FDN não foi alterado $(\mathrm{P}>0,10)$ nas diferentes silagens avaliadas, observando-se consumo médio de 5,35 kg de FDN, equivalente a 1,18\% do peso corpóreo. Da mesma forma, não houve diferença significativa $(\mathrm{P}>0,10)$ entre os tratamentos para as taxas de ingestão de FDN e de mastigação de FDN. O consumo de MS da ração total também não apresentou diferença significativa $(\mathrm{P}>0,10)$ nos tratamentos em que se avaliou o efeito de enzimas fibrolíticas, nos quais se observou consumos médios de 2,13 e 1,97\% do peso corpóreo para os tratamentos com silagem emurchecida e não-emurchecida, respectivamente.

Ao comparar silagens com e sem emurchecimento, verificou-se maior $(\mathrm{P}<0,05)$ consumo $(\mathrm{kg} \mathrm{MS} / \mathrm{dia}$ e \% peso vivo) para silagens emurchecidas. $\mathrm{O}$ uso de enzimas fibrolíticas na ensilagem ou pouco antes do fornecimento ao animal não foi efetivo para aumentar o consumo. Embora tenha sido observado menor teor de FDN nas rações contendo silagens emurchecidas $(\mathrm{P}<0,05)$, a ingestão de FDN não foi alterada entre os tratamentos impostos, confirmando o conceito sugerido por Mertens (1997) e Armentano \& Pereira (1997).

$\mathrm{Na}$ análise da digestibilidade aparente no trato digestivo total (Tabela 4), verificou-se diferença significativa $(\mathrm{P}<0,05)$ do efeito de emurchecimento para MS, MO, FDN, FDA e hemicelulose. De modo geral, as silagens emurchecidas apresentaram maiores teores de carboidratos solúveis, proteínas e cinzas, resultando em menor participação das frações de FDN e celulose na composição da MS e menor proporção de MO na MS que as silagens contendo umidade original (Tabela 1). Com base nesse perfil de composição, seriam esperadas maiores digestibilidades da MS e da MO para silagens emurchecidas que para silagens úmidas, ao contrário dos resultados obtidos (Tabela 4). Em silagens úmidas, a lixiviação de minerais via efluente representa perda qualiquantitativa da fração mineral (McDonald et al., 1991). O menor coeficiente de digestibilidade da MS em silagens emurchecidas poderia ser explicado, ao menos parcialmente, pela hipótese do rompimento de células ocorrido com o emurchecimento, o extravasamento e a lixiviação da fração mineral mais solúvel presente na forragem fresca (Coelho, 2002). Embora tanto o efluente de silagens úmidas como o extravasamento celular de silagens emurchecidas possam determinar perdas na fração mineral, os efeitos observados na digestibilidade da MS (Tabela 4) seriam explicados se a intensidade dessas perdas fosse maior e mais seletiva durante o emurchecimento.

A aplicação da técnica de emurchecimento em forragens reduziu significativamente a digestibilidade da MO em relação às silagens não-emurchecidas $(47,27$ e $56,01 \%$ ) (Tabela 4$)$, provavelemente em decorrência da maior proporção de lignina na fração de FDN, tanto nas silagens ( 7,77 vs. $6,65 \%)$ como nas rações $(8,20$ vs. $7,43 \%)$, conforme apresentado na Tabela 1. Os maiores coeficientes de digestibilidade das frações fibrosas (FDN, FDA) em silagens nãoemurchecidas (Tabela 4) confirmam essa hipótese.

Dos contrastes entre os tratamentos testados (Tabela 4), somente para as variáveis FDN e FDA, foram observados efeitos de momento da aplicação das enzimas fibrolíticas na silagem, verificando-se maiores coeficientes de digestibilidade (58,21 vs. $51,99 \%$ e 58,55 vs. $50,79 \%$, respectivamente) quando se adicionou a solução enzimática na forragem 30 minutos antes do fornecimento ao animal. Esses resultados indicam que a aplicação da preparação enzimática minutos antes da oferta da ração foi mais eficaz na elevação da digestibilidade aparente da fração fibrosa que a aplicação na ensilagem. No tratamento em que as enzimas fibrolíticas foram aplicadas na ensilagem, houve redução de $3,35 \%$ para a FDN, 3,58\% para FDA e 2,95\% para celulose, em relação ao tratamento com aplicação da enzima após a abertura do silo, o que pode indicar que a aplicação das enzimas fibrolíticas no início da ensilagem tenha proporcionado maior tempo de atuação da enzima com a forragem que a aplicação minutos antes do fornecimento ao animal.

Em geral, nos experimentos contendo enzimas fibrolíticas, a maior efetividade desses complexos é caracterizada por redução na fração fibrosa e conseqüente diminuição da digestibilidade da fibra da forragem (Kung Jr., 2000). Neste experimento, apesar de não avaliado, existe a possibilidade de que a porção mais digestível dos componentes fibrosos (FDN e FDA) tenha permanecido intacta ou pouco alterada, justificando os maiores valores de digestibilidade dessas frações quando o complexo enzimático foi adicionado à silagem antes do fornecimento ao animal, em relação à aplicação na ensilagem. 
Tabela 4 - Ingestão de MS e de FDN e digestibilidade aparente de nutrientes em rações contendo silagens de capimtanzânia com e sem adição de enzimas fibrolíticas

Table 4 - Intake of DM and NDF and nutrient digestibility of rations containing Tanzaniagrass silage with or without fibrolytic enzymes addition

\begin{tabular}{|c|c|c|c|c|c|c|c|c|c|c|}
\hline \multirow[t]{2}{*}{$\begin{array}{l}\text { Variável } \\
\text { Variable }\end{array}$} & \multicolumn{5}{|c|}{$\begin{array}{l}\text { Tratamento } \\
\text { Treatment }^{1}\end{array}$} & \multirow[t]{2}{*}{$\mathrm{CV}(\%)$} & \multicolumn{4}{|c|}{$\begin{array}{c}\text { Contraste }(\mathrm{P}<)^{2} \\
\text { Contrast }\end{array}$} \\
\hline & A & B & $\mathrm{C}$ & $\mathrm{D}$ & E & & 1 & 2 & 3 & 4 \\
\hline \multicolumn{11}{|l|}{ Ingestão (Intake) } \\
\hline $\begin{array}{l}\text { MS (DM) } \\
\text { kg MS/dia } \\
\text { kgDM/day }\end{array}$ & 11,06 & 9,82 & 10,44 & 10,22 & 9,74 & 9 & $*$ & $\mathrm{~ns}$ & $\mathrm{~ns}$ & $\mathrm{~ns}$ \\
\hline $\begin{array}{l}\text { kg MS (\%peso vivo) } \\
\operatorname{kgDM}(\% \text { body weight })\end{array}$ & 2,20 & 1,94 & 2,05 & 2,03 & 1,94 & 8 & $*$ & ns & ns & $\mathrm{ns}$ \\
\hline \multicolumn{11}{|l|}{ FDN $(N D F)$} \\
\hline FDN ração $(\%)$ & 47,98 & 50,39 & 48,01 & 49,60 & 51,01 & 3 & $* *$ & $\mathrm{~ns}$ & $\mathrm{~ns}$ & $\mathrm{~ns}$ \\
\hline \multicolumn{11}{|l|}{ Ration NDF (\%) } \\
\hline $\mathrm{kg} \mathrm{NDF/day}$ & & & & & & & & & & \\
\hline $\begin{array}{l}\text { kg FDN (\% peso vivo) } \\
\text { kgNDF (\% body weight) }\end{array}$ & 1,11 & 1,03 & 1,05 & 1,06 & 1,05 & 8 & $\mathrm{~ns}$ & $\mathrm{~ns}$ & $\mathrm{~ns}$ & $\mathrm{~ns}$ \\
\hline \multicolumn{11}{|c|}{ 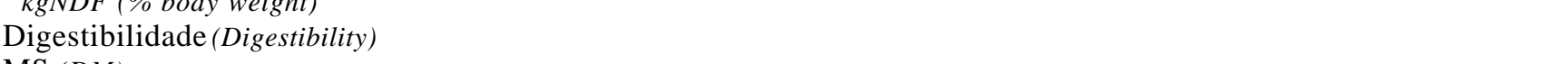 } \\
\hline \multicolumn{11}{|l|}{$\operatorname{MS}(D M)$} \\
\hline $\mathrm{kg} / \mathrm{dia}(\mathrm{kg} /$ day $)$ & 4,91 & 5,70 & 5,45 & 5,64 & 6,01 & 14 & $*$ & ns & $\mathrm{ns}$ & $\mathrm{ns}$ \\
\hline \multicolumn{11}{|l|}{ MO $(O M)$} \\
\hline$\%$ & 45,72 & 55,66 & 48,81 & 54,93 & 57,46 & 11 & $* *$ & $\mathrm{~ns}$ & $\mathrm{~ns}$ & $\mathrm{~ns}$ \\
\hline $\mathrm{kg} / \mathrm{dia}(\mathrm{kg} /$ day $)$ & 4,41 & 5,50 & 4,91 & 5,43 & 5,78 & 16 & * & $\mathrm{ns}$ & $\mathrm{ns}$ & $\mathrm{ns}$ \\
\hline \multicolumn{11}{|l|}{$\mathrm{FDN}(N D F)$} \\
\hline$\%$ & 45,74 & 54,74 & 45,86 & 51,99 & 58,21 & 9 & $* *$ & $\mathrm{~ns}$ & $\mathrm{~ns}$ & * \\
\hline $\mathrm{kg} / \mathrm{dia}(\mathrm{kg} /$ day $)$ & 2,50 & 3,14 & 2,57 & 2,95 & 3,46 & 17 & $* *$ & $\mathrm{~ns}$ & $\mathrm{~ns}$ & $\dagger$ \\
\hline \multicolumn{11}{|l|}{ FDA $(A D F)$} \\
\hline$\%$ & 45,36 & 55,06 & 45,19 & 50,79 & 58,55 & 11 & $* *$ & $\mathrm{~ns}$ & $\mathrm{~ns}$ & * \\
\hline kg/dia (kg/day) & 1,30 & 1,69 & 1,32 & 1,49 & 1,88 & 21 & $* *$ & $\mathrm{~ns}$ & $\mathrm{~ns}$ & $*$ \\
\hline \multicolumn{11}{|c|}{ Hemicelulose (Hemicellulose) } \\
\hline$\%$ & 46,05 & 54,24 & 46,45 & 53,02 & 57,64 & 9 & $* *$ & $\mathrm{~ns}$ & $\mathrm{~ns}$ & $\mathrm{~ns}$ \\
\hline $\mathrm{kg} / \mathrm{dia}(\mathrm{kg} /$ day $)$ & 1,20 & 1,45 & 1,24 & 1,45 & 5,17 & 17 & $* *$ & $\mathrm{~ns}$ & $\mathrm{~ns}$ & $\mathrm{~ns}$ \\
\hline
\end{tabular}

${ }^{1}$ Tratamentos = A - silagem emurchecida; B - silagem sem emurchecimento; C - silagem emurchecida com enzimas; D - silagem sem emurchecimento com enzimas; $\mathrm{E}$ - silagem sem emurchecimento com enzimas aplicadas após abertura do silo. (Treatments $=A-$ wilted forage, without enzymes; $B$ - fresh forage, without enzymes; $C$ - wilted forage with enzymes at ensiling; $D$ - fresh forage, with enzymes at ensiling; $E$ - fresh forage with enzymes applied onto silage 30 minutes before feeding (direct-fed)).

${ }^{2}$ Contrastes $=1$. Efeito emurchecimento $(A+C$ vs. $B+D+E)$, 2. Efeito enzimas - emurchecimento (A vs. C), 3. Efeito enzimas - sem emurchecimento (B vs. D+E), 4. Efeito do momento de aplicação da enzima (D vs. E)

${ }^{2}$ Contrasts $=1$. Wilting effect $(A+C$ versus $B+D+E) ; 2$. Enzymes effect -wilting $(A$ vs. $C)$. 3. Enzymes effect - wet $(B$ vs. $D+E)$ and 4 . Enzymes application time ( $D$ vs $E)$ ).

$\mathrm{MS}=$ Matéria seca (Dry matter), $\mathrm{MO}=$ Matéria orgânica (Organic matter), FDN= Fibra em detergente neutro (Neutral detergent fiber), FDA= Fibra em detergente ácido (Acid detergent fiber).

ns: não-significativo, ${ }^{*}(P<0,05),{ }^{* \star}(P<0,01), \dagger(P<0,10)$ (ns: not significant, $\left.{ }^{*}(P<.05),{ }^{* *}(P<.01),+(P<.10)\right)$.

\section{Conclusões}

O emurchecimento da forragem e o uso de aditivo enzimático resultaram em alterações marginais nos parâmetros ruminais e no comportamento ingestivo dos animais. A aplicação da preparação enzimática minutos antes do fornecimento da ração proporcionou os melhores resultados sobre a digestibilidade da fração fibrosa, indicando que, talvez, essa forma de aplicação seja o método mais adequado para garantir maior efetividade das enzimas fibrolíticas.

\section{Agradecimento}

À Fundação de Amparo a Pesquisa do Estado de São Paulo, pelo apoio financeiro ao projeto e pela concessão de bolsas de estudo.

\section{Literatura Citada}

ANIWARU, A.; ISHIDA, T.; WATANABE, T. et al. The effect of cellulase on cell wall structure and the rumen digestion of timothy silage. In: INTERNATIONAL GRASSLAND CONGRESS, 19., 2001, São Pedro. Anais... Manaus: 
Sonopress, 2001. CD-ROM. Forage Conservation. Papers, 21-16.

ARMENTANO, L.; PEREIRA, M. Measuring the effectiveness of fiber by animal response trials. Journal of Dairy Science, v.80, n.7, p.1416-1425, 1997.

BEAUCHEMIN, K.A.; BUCHANAN-SMITH, J.G. Effects of neutral detergent fiber concentration and supplementary long hay on chewing activities and milk production of dairy cows. Journal of Dairy Science, v.72, n.9, p.2288-2300, 1989.

BEAUCHEMIN, K.A.; RODE, L.M. The potential use of feed enzymes for ruminants. In: CORNELL NUTRITION CONFERENCE FOR FEED MANUFACTURERS, 1996, New York. Proceedings... New York: Rochester Marriott Thruway Hotel, 1996. p.131-141.

BEAUCHEMIN, K.A.; COLOMBATTO, D.; MORGAVI, D.P. et al. Use of exogenous fibrolytic enzymes to improve feed utilization by ruminants. Journal of Animal Science, v.81, E suppl. 2, p.E37-E47, 2002.

BERGMAN, E.N. Energy contributions of volatile fatty acids from the gastrointestinal tract in various species. Physiological Reviews, v.70, p.567-590, 1990.

CHANEY, A.L.; MARBACH, E.P. Modified reagents for determination of urea and ammonia. Clinical Chemistry, v.8, n.2, p.130-137, 1962.

COELHO, R.M. Efeito da concentração de matéria seca e do uso de inoculante bacteriano-enzimático, na silagem de Tifton-85 (Cynodon ssp.), sobre a digestão de nutrientes, parâmetros ruminais e comportamento ingestivo em novilhos de corte em crescimento. Piracicaba: Escola Superior de Agricultura "Luiz de Queiroz", 2002. 136p. Dissertação (Mestrado em Produção Animal) - Escola Superior de Agricultura "Luiz de Queiroz", 2002.

DUBOIS, M.K.; GILLES, K.A.; HAMILTON, J.K. et al. Colorimetric method for determination of sugars and related substances. Analytical Chemistry, v.28, p.350-356, 1956.

FENG, P.; HUNT, C.W.; JULIEN, W. E. et al. Effect of enzymes additives on in situ and in vitro degradation of mature coolseason grass forage. Journal of Animal Science, v.70, suppl. 1, p.309, 1992.

FONTES, C.M; HALL J.; HIRST, B.H. et al. The resistance of cellulases and xylanases to proteolytic inactivation. Applied Microbiology and Biotechnoly, v.43, p.52-57, 1995.

HENDERSON, N. Silage additives. Animal Feed Science and Technology, v.45, p.35-56, 1993.

HUBER, J.T.; KUNG JR., L. Protein e nonprotein utilization in cattle. Journal of Dairy Science, v.64, n.6, p.1170-1195, 1981.

IGARASI, M.S. Controle de perdas na ensilagem de capim Tanzânia (Panicum Maximum Jacq. cv Tanzânia) sob os efeitos do teor de matéria seca, do tamanho de partícula, da estação do ano e da presença do inoculante bacteriano. Piracicaba: Escola Superior de Agricultura "Luiz de Queiroz", 2002. 132p. Dissertação (Mestrado) - Escola Superior de Agricultura "Luiz de Queiroz", 2002.

ISHIDA, T.; AISAN, A.; TOMIYAMA, K. et al. The effect of cellulase on cell wall structure and the rumen digestion of alfalfa silage. In: INTERNATIONAL GRASSLAND CONGRESS, 19., 2001, São Pedro. Anais... Manaus: Sonopress, 2001. CDROM. Forage Conservation. Papers, ID 21-17.

KUNG JR., L.; GRIEVE, D.B.; THOMAS, J.W. et al. Added ammonia or microbial inocula for fermentation and nitrogenous compounds of alfalfa ensiled at various percents of dry matter. Journal of Dairy Science, v.67, n.2 , p. 299-306, 1984.

KUNG JR., L. Microbial and chemical additives for silage - effects on fermentation and animal response. In: WORKSHOP SOBRE MILHO PARA SILAGEM, 2000, 2., Piracicaba. Anais...
Piracicaba: Fundação de Estudos Agrários "Luiz de Queiroz", 2000. p.53-73.

LAMMERS, B.P.; BUCKMASTER, D.R.; HEINRICHS, J.A simple method for the analysis of particle sizes of forages and total mixed rations. Journal of Dairy Science, v.79, n.5, p.922-928, 1996.

LEWIS, G.E.; HUNT, C.W.; SANCHEZ, W.K. et al. Effect of directfed fibrolytic enzymes on the digestive characteristics of a forage-based diet fed to beef steers. Journal of Animal Science, v.74, p.3020-3028, 1996.

MAEKAWA, M.; BEAUCHEMIN, K.A.; CHRISTENSEN, D.A. Chewing 1416-1425activity, saliva production, and ruminal $\mathrm{pH}$ of primiparous and multiparous lactating dairy cows. Journal of Dairy Science, v.85, p.1176-1182, 2002.

MARTINS, A.S.; BERCHIELLI, P. F.V.; PRADO, I. N. et al. Efeito da adição de enzimas fibrolíticas à ração sobre os parâmetros ruminais em bovinos alimentados com silagem de milho e feno de Tifton 85. In: REUNIÃO ANUAL DA SOCIEDADE BRASILEIRA DE ZOOTECNIA, 39., 2002, Recife. Anais... Caucaia: CD+, 2002, CD-ROM. Nutrição de ruminantes.

McDONALD, P.; HENDERSON, A.R.; HERON, S.J.E. The biochemistry of silage. 2.ed. Marlow: Chalcombe, 1991. 340p.

MERTENS, D.R. Creating a system for meeting the fiber requirements of dairy cows. Journal of Dairy Science, v.80, p.1463-1481, 1997.

MUCK, R.E.; KUNG JR., L. Effects of silages additives on ensiling. In: THE SILAGE: FIELD TO FEED BUNK NORTH AMERICAN CONFERENCE, 1997, Hershey. Proceedings... Hershey: National Regional Agricultural Engineering Service. 1997. p.187-199.

OKUDA, H.; FUGI, S.; KAWASHIMA. A direct colorimetric method for blood ammonia. Journal of Experimental Medicine. v.12, n.1, p.11-23,1965.

ORSKOV, E.R.; McDONALD, I. The estimation of protein degradability in the rumen from incubation measurements weight according to rate of passage. Journal of Agricultural Science, v.92, p.499-503, 1979.

PITT, R. E. Additives for silage and hay preservation. In: SILAGE AND HAY PRESERVATION, New York, 1990. NRAES-5. New York: Ithaca, 1990. p.28-44.

STATISTICAL ANALYSES SYSTEM - SAS. SAS/STAT. User's Guide. Version 8. Cary: 2000.

SATTER, L.D.; SLYTER, L.L. Effect of ammonia concentration on rumen microbial protein production in vitro. British Journal of Nutrition, v.32, n.2, p.199-208, 1974.

SILVA, D.J. Análise de alimentos: métodos químicos e biológicos. Viçosa, MG: Universidade Federal de Viçosa, 1990. 165p.

UDÉN, P.; COLUCCI, P.E.; Van SOEST, P.J. Investigation of chromium, cerium, and cobalt as markers in digesta. Rate of passage studies. Journal of the Science of Food and Agriculture, v.31, n.7, p.625-632, 1980.

Van SOEST, P.J.; ROBERTSON, J.B.; LEWIS, B.A. Methods for dietary fiber, neutral detergent fiber, and non-starch polysaccharides in relation to animal nutrition. Journal of Dairy Science, v.74, p.3583-3597, 1991.

WOOLFORD, M.K. The silage fermentation. New York: Marcel Dekker, 1984. 322p.

WILES, P.G.; GRAY, I.K.; KISSLING, R.C. Routine analysis of protein by Kjeldahl and Dumas methods: review and interlaboratory study using dairy products. Journal of AOAC International, v.81, n.3, p.620-632, 1998.

Recebido em: 12/02/04 Aceito em: 13/04/05 